152

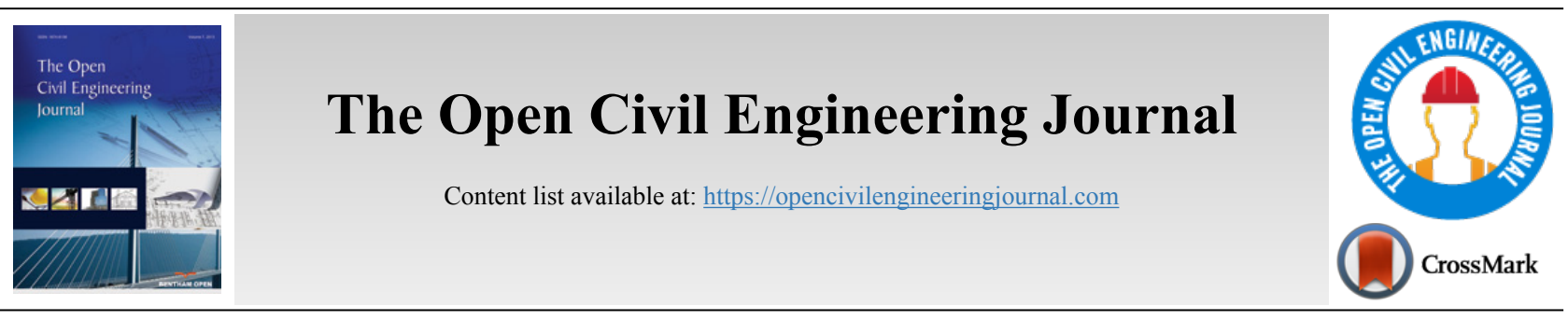

RESEARCH ARTICLE

\title{
Laboratory Tests on Hydraulic Lime Mortar Reinforced With Jute Fibres
}

\author{
Antonio Formisano ${ }^{1, *}$, Giovanni Chiumiento ${ }^{1}$ and Enzo J. Dessì ${ }^{1}$ \\ ${ }^{\prime}$ Department of Structures for Engineering and Architecture, University of Naples “Federico II”, Piazzale Tecchio 80, 80125 Naples, Italy
}

\begin{abstract}
:
Background:

Considering the high seismic vulnerability of masonry buildings located in the Italian territory, the implementation of seismic retrofit programs is strongly needed.. With consideration for sustainable interventions, it is evident that the retrofit techniques to protect the historical heritage should be carried out with innovative green compound materials, such as mortars reinforced with natural fibres.

\section{Objective:}

In the current paper, laboratory tests on lime mortars strengthened with raw jute fibres have been performed.

Methods:

The workability of the fibre-reinforced mixture has been assessed through shaking table tests, and the mechanical resistances of standard specimens have been evaluated by bending and compression tests.

Results:

Considering the hygroscopic nature of jute, it has been identified that the optimal water/lime ratio and the maximum water percentage are absorbed by jute fibres. From the results, how the spreading of the mixture, which is indicative of the mortar consistency, changes with the water/lime ratio, has been evaluated. From bending tests, the effective behaviour of fibres, which provide a stitching effect of the failure crack in the investigated fibre-reinforced lime mortars, has been observed.

Conclusion:

Finally, the results of compression tests have shown that the examined fibre-reinforced mortars can be effectively used as building products according to the actual Italian technical code NTC 2018.
\end{abstract}

Keywords: Masonry structures, Plaster, Lime mortar, Jute fibres, Flexural stress, Compression strength.

\begin{tabular}{|l|l|l|l|}
\hline Article History & Received: November 05, 2019 & Revised: January 13, 2020 & Accepted: April 12, 2020 \\
\hline
\end{tabular}

\section{INTRODUCTION}

Looking at the data of the ISTAT census in 2011 [1], in Italy, there are more than 12 million residential buildings, of which $57.24 \%$ are made of masonry. Over $90 \%$ of these buildings were built before ' 90 s without fulfilling antiseismic criteria. Moreover, the conservation state of a large part of this historical heritage is not satisfactory. As a consequence, the vulnerability level of Italian masonry structures is very high $[2,3]$, so to often require seismic improvement and retrofitting interventions [4]. In this framework, based on a renewed sensitiveness towards eco-friendly and natural materials, the

\footnotetext{
* Address correspondence to this author at the Department of Structures for Engineering and Architecture, University of Naples "Federico II", Piazzale Tecchio 80, 80125Naples, Italy E-mail: antoform@unina.it
}

use of lime or cement mortars reinforced with natural fibres [5 - 7] opens new and wider perspectives in the field of green composite plasters as reinforcing system of masonry structures.

In the field of natural fibres used in the textile field, jute, known for the colour as golden fibres, is second only to cotton in terms of usage, production and global consumption. Jute plants are easy to grow, have a high yield per acre and, unlike cotton, have little need for pesticides and fertilizers. Jute is a best fibre, like flax and hemp, and the stems are processed in a similar way. This green material is environmentally friendly, $100 \%$ recyclable, and has high physical and mechanical features [8], which are similar to the hemp ones. On the other hand, compared to hemp, jute is completely free of narcotics or odorous elements, and has a less basic cost, which makes it 
extremely competitive on the market.

Jute fibres are very long ( 1 to 4 metres), silky, lustrous and with a golden brown colour. In contrast to most textile fibres, which consist mainly of cellulose, jute fibres are made of cellulose and lignin. Cellulose is the major component of plant fibres, while lignin is the main constituent of wood fibres; jute is, therefore, partly a textile fibre and partly a wood fibre.

Jute is used in shopping bags, carpets and rugs, backing for linoleum floor covering, chair coverings and environmentally friendly coffins. Jute is also useful as a geotextile fabric laid to stabilise soil against landslides and to control erosion or weeds. The fabric helps to keep the moisture and holds the soil in place, whilst its open weave structure allows space for plants to grow.

In the construction field, jute fibres are currently employed as reinforcement of composite polymeric materials [9] and for the packaging of concretes [10] in developing areas, such as India and Bangladesh. In literature, experimental tests were performed in order to evaluate both the durability of these fibres embedded in a cement matrix and the degradation of the wet fibres [11]. The achieved results were comparable to those found in the experimentations on hemp fibres [12].

Considering the high potentialities of this natural material, in the current paper, an experimental program on lime mortars reinforced with jute fibres is presented and discussed in order to highlight the benefits deriving from their use in terms of both workability [13] and bending [14, 15] and compression strengths of the mixture.

\section{MATERIALS AND METHODS}

\subsection{Targets}

A binder (cement or lime) mixed with water and fine aggregates must ensure adequate workability for packaging and certain benefits in the solid-state in mechanical, chemical and physical terms. Through the use of composite materials, it is possible to increase the efficiency and performance of the basic material, providing new features resulting from the synergy with the reinforcement fibres [16].

The objective of the presented research work, developed

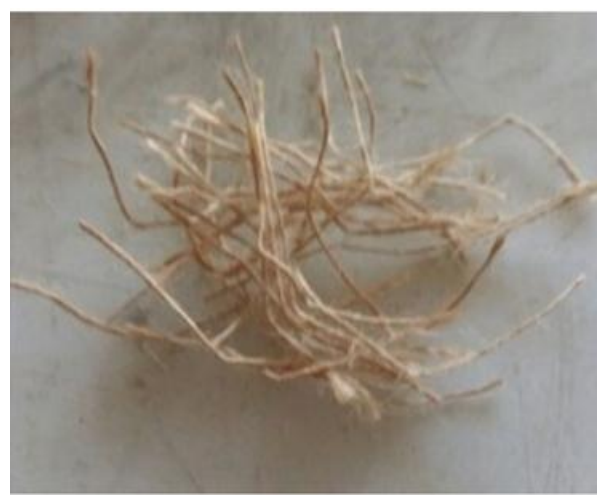

a) for packaging of doughs of hydrated lime mortar reinforced with jute fibres, is the determination of the following parameters:

- Optimal water/lime (W/L) ratio, considering both the percentage of jute fibres as a fixed parameter and the amount of water absorbed by natural fibres through imbibition.

- Best percentage of fibres, when the W/L ratio is assumed to be constant;

- Bending and compression strengths of specimens after ageing of 28 days. In the design phase, the precise assessment of the material mechanical properties can be very important to limit the uncertainties in structural evaluation [17].

\subsection{Materials}

The components of the mixture are raw jute fibres, whose main properties derived from literature are listed in Table 1, and M15 class Kerakoll Geocalce ${ }^{\circledR}$ binder, having characteristics conforming to the UNI EN 998-1 [18] and UNI EN 998-2 [19] standards.

Table 1. Physical and mechanical properties of jute fibres [10].

\begin{tabular}{|c|c|}
\hline Feature & Value \\
\hline Fibre diameter $(\phi)$ & $20 \div 200 \mu \mathrm{m}$ \\
\hline Relative density $(\rho)$ & $13 \div 14.9 \mathrm{kN} / \mathrm{m}^{3}$ \\
\hline Yielding stress $\left(\mathrm{f}_{\mathrm{yk}}\right)$ & $320 \div 800 \mathrm{MPa}$ \\
\hline Elastic modulus $(\mathrm{E})$ & $\approx 30000 \mathrm{MPa}$ \\
\hline Ultimate strain $\left(\varepsilon_{\mathrm{u}}\right)$ & $1.0 \div 1.8 \%$ \\
\hline $\begin{array}{c}\text { Absorption at } 65 \% \text { of relative humidity (r.h.) and } \\
\mathrm{T}=20^{\circ} \mathrm{C}\end{array}$ & $12 \%$ \\
\hline $\begin{array}{c}\text { Difference in desorption and absorption (r.h.65\% } \\
\left.\text { and } \mathrm{T}=20^{\circ} \mathrm{C}\right)\end{array}$ & $1 \div 5 \%$ \\
\hline Thermal conductivity (dry condition) & $0.05 \div 0.055 \mathrm{~W} / \mathrm{mK}$ \\
\hline
\end{tabular}

The jute fibres on the market are of "long" type (length of about $15 \div 20 \mathrm{~cm}$ ) and cannot be used for packaging of standard specimens used for mechanical tests. Therefore, they are cut and blended in order to obtain respectively "medium" fibres (Fig. 1a), having a length between 5 and $15 \mathrm{~mm}$, and flakes (Fig. 1b).

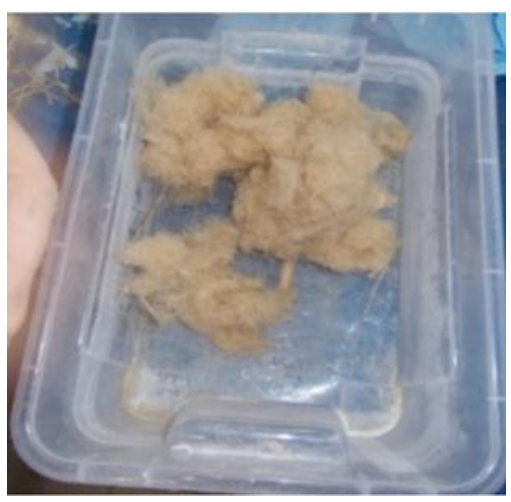

b)

Fig. (1). Fibres (a) and flakes (b) of jute. 


\subsection{Test Procedure}

For packaging of fibre-reinforced lime mortars, a mixer with steel cup and perforated mixing paddle, connected to a speed electronic control system, has been used according to the EN196-1 standard [20]. The mixer is able to work on either the mixture total mass or the fresh grout volume according to the limits of the before the mentioned standard. In the absence of specific indications, the fresh grout sample can be brought to a consistency limit value Table $\mathbf{2}$, expressed as grout spreading diameter, determined according to the UNI EN 1015-3 standard [21], where a shaking table is used to evaluate the mixture water content.

The used apparatus consists of a circular table with a shaft, mounted on a sturdy frame, which applies the vertical shock to the grout placed inside a bronze cone, having a diameter between $70 \mathrm{~mm}$ and $100 \mathrm{~mm}$. The cone filling takes place in two successive phases: in each phase the grout is compacted

Table 2. Grout consistency evaluation.

\begin{tabular}{|c|c|}
\hline $\begin{array}{c}\text { Density of the Fresh Grout Mixture } \\
\left(\mathbf{k N} / \mathbf{m}^{\mathbf{3}}\right)\end{array}$ & Spreading Diameter $(\mathbf{m m})$ \\
\hline$>12$ & $175 \pm 10$ \\
\hline $6 \div 12$ & $160 \pm 10$ \\
\hline $3 \div 6$ & $140 \pm 10$ \\
\hline$\leq 3$ & $120 \pm 10$ \\
\hline
\end{tabular}

with 25 strokes in order to ensure an uniform filling. Therefore, after 30 seconds, the cone is uplifted and shaking is applied for 15 seconds. When shaking is terminated, the grout spreading, expressed in millimetres, along two orthogonal diameters is measured. The test is performed considering two grout specimens, and the spreading value is given by the average value of the two measurements. In order to have a good workability of the grout to be used for plaster, a spreading of the lime grout defined according to the UNI 998-1/-2 standards $[18,19]$ is needed. Aiming at defining the water absorption quantity of jute fibres, they are completely immersed in water under standard environmental conditions (r.h. $65 \%$ and $\mathrm{T}=$ $20^{\circ} \mathrm{C}$ ) for times of 10, 30, 60 and 120 minutes. At the end of each analysis step, they are extracted from the water, wiped with a cloth to remove the excess water and weighted to compute the absorbed water.

The specimens used for mechanical flexural tests [22] have standard dimensions of $40 \times 40 \times 160 \mathrm{~mm}$ defined according to the UNI EN 196-1 standard [20]. The specimens are manufactured with a steel normalized drawer. After seven days, they are removed from the formworks and, subsequently, are subjected to the curing process under normal environmental conditions for 21 days. Three-point bending tests at a rate of $0.01 \mathrm{~mm} / \mathrm{s}$ are performed using a transducer placed in the centre of samples to monitor the mid-span displacements.

\section{RESULTS OF TESTS}

\subsection{Water Absorption of Jute Fibres}

The tests are conducted on three samples manufactured with $10 \mathrm{~g}$ of medium-size jute fibres and immersed in water. The samples are weighted at different intervals until 120 minutes (Table 3). Through these tests, it is obtained the complete water imbibition of fibres. The average final weight of fibres $\mathrm{W}_{\mathrm{f} \text {,avg }}$ is equal to $41.30 \mathrm{~g}$. Compared to the average initial weight of fibres $\mathrm{W}_{\mathrm{i} \text {,avg }}=10.64 \mathrm{~g}$, an average water amount $\mathrm{W}_{\mathrm{w}, \text { avg }}=30.66 \mathrm{~g}$ is required for the complete imbibition.

The tests are performed by fully soaking the fibres in water. From the tests, it is noted that the weight of fibres, compared to their initial weight, is increased by about 3 times. Analyzing the data (Fig. 2), it is noticed that fibers achieved the maximum gain in weight after 30 minutes of soaking, and no weight gain is recorded with further soaking. However, it is noted that, during the tests, the likely dimension variations of fibres are not measured.

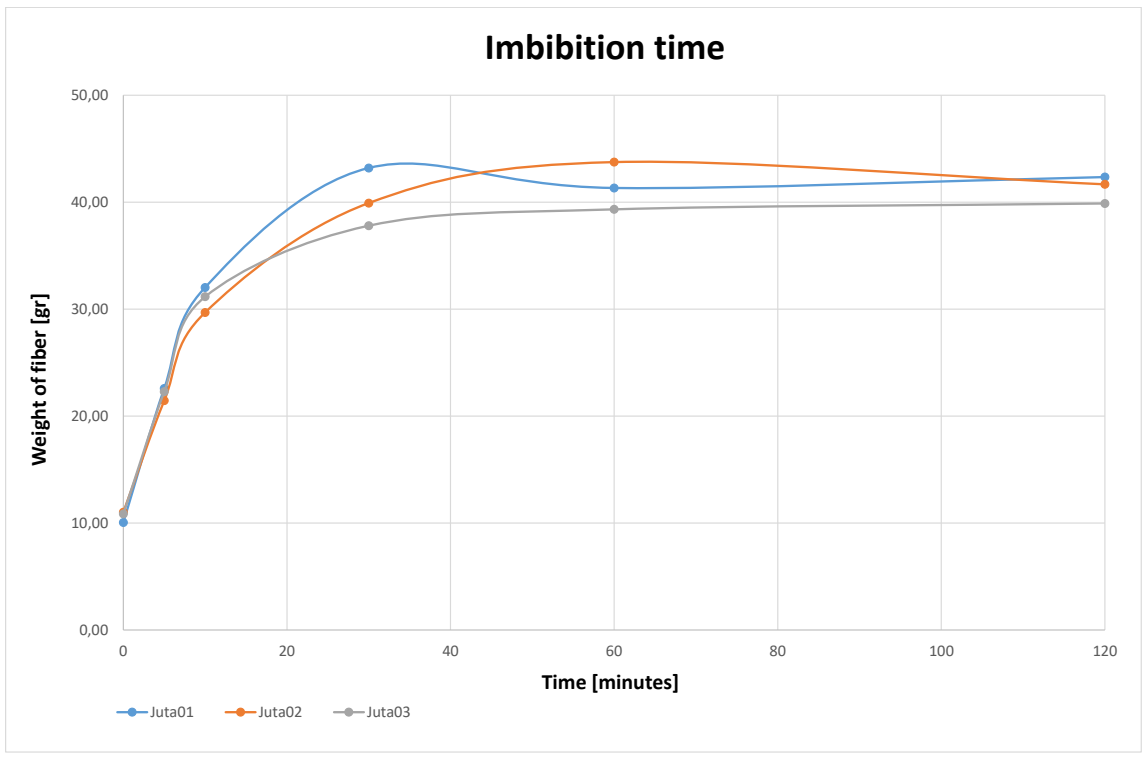

Fig. (2). Water imbibition time of jute fibres. 
Table 3. Tests for the imbibition of fibres.

\begin{tabular}{|c|c|c|c|c|c|c|}
\hline Sample & $\mathbf{T}=\mathbf{0}^{\prime}$ & $\mathbf{T}=\mathbf{5}$, & $\mathbf{T}=\mathbf{1 0} \boldsymbol{\prime}^{\prime}$ & $\mathbf{T}=\mathbf{3 0} \boldsymbol{\prime}^{\prime}$ & $\mathbf{T = 6 \boldsymbol { \prime } ^ { \prime }}$ & $\mathbf{T}=\mathbf{1 2 0} \boldsymbol{\prime}^{\prime}$ \\
\hline 1 & $10,05 \mathrm{~g}$ & $22,59 \mathrm{~g}$ & $32,03 \mathrm{~g}$ & $43,20 \mathrm{~g}$ & $41,33 \mathrm{~g}$ & $42,35 \mathrm{~g}$ \\
\hline 2 & $11,02 \mathrm{~g}$ & $21,44 \mathrm{~g}$ & $29,69 \mathrm{~g}$ & $39,92 \mathrm{~g}$ & $43,75 \mathrm{~g}$ & $41,67 \mathrm{~g}$ \\
\hline 3 & $10,86 \mathrm{~g}$ & $22,28 \mathrm{~g}$ & $31,16 \mathrm{~g}$ & $37,80 \mathrm{~g}$ & $39,33 \mathrm{~g}$ & $39,88 \mathrm{~g}$ \\
\hline
\end{tabular}

$\mathrm{T}=$ time expressed in minutes

\subsection{Maximum Water Percentage in the Lime Mortar Grout}

The manufacturer indicates a minimum water/lime ratio $\left(\mathrm{W} / \mathrm{L}_{\text {min }}\right.$ ) equal to $20 \%$ for M15 lime grout. Through different workability tests on five lime mortar samples manufactured without fibres, a maximum $\mathrm{W} / \mathrm{L}$ ratio of $21,5 \%$ is recorded (Table 4).

Table 4. Consistency tests on lime mortar samples with different percentages of water.

\begin{tabular}{|c|c|c|c|c|}
\hline Sample & $\begin{array}{c}\text { Lime Weight } \\
\text { (g) }\end{array}$ & $\begin{array}{c}\text { Water } \\
\text { Weight } \\
\text { (g) }\end{array}$ & $\begin{array}{c}\text { Water/Lime } \\
\text { Ratio } \\
\text { (/) }\end{array}$ & $\begin{array}{c}\text { Spreading } \\
\text { Value } \\
(\mathbf{m m})\end{array}$ \\
\hline 1 & 1001 & 200 & 0,200 & 161 \\
\hline 2 & 1000 & 205 & 0,205 & 170 \\
\hline 3 & 1005 & 210 & 0,210 & 180 \\
\hline 4 & 1002 & 215 & 0,215 & 192 \\
\hline 5 & 1000 & 220 & 0,220 & $(*)$ \\
\hline
\end{tabular}

(*) unsatisfactory consistency test

\subsection{Water Percentage in the Fibre-Reinforced Mixture}

In order to prepare the mixtures, the water total amount to be used is considered as the sum of three parts: the first indicated by the manufacturer, the second absorbed by fibres and the third required to ensure the grout workability. After the water quantity absorbed by jute fibres is identified, a series of mixtures are packed using lime weight of $1000 \mathrm{~g}$, jute fibres

Table 5. Consistency tests on fibre-reinforced samples manufactured with different $\mathrm{W} / \mathrm{L}$ percentages.

\begin{tabular}{|c|c|c|c|}
\hline Sample & $\begin{array}{c}\text { Water weight } \\
(\mathbf{g})\end{array}$ & $\begin{array}{c}\text { W/L) } \\
(/)\end{array}$ & Spreading Value (mm) \\
\hline 1 & 200,0 & 0,200 & $(*)$ \\
\hline 2 & 207,5 & 0,208 & $(*)$ \\
\hline 3 & 215,0 & 0,215 & $(*)$ \\
\hline 4 & 222,5 & 0,223 & $(*)$ \\
\hline 5 & 230,0 & 0,230 & 120 \\
\hline 6 & 237,5 & 0,238 & 141 \\
\hline 7 & 245,0 & 0,245 & 161 \\
\hline 8 & 252,5 & 0,253 & 177 \\
\hline 9 & 260,0 & 0,260 & 192 \\
\hline
\end{tabular}

(*) unsatisfactory consistency test

weight of $10 \mathrm{~g}$ (corresponding to $1 \%$ of the binder weight) and variable quantities of water starting from $200 \mathrm{~g}$, as indicated by the manufacturer. The used amount of fibres allows to have an incombustible composite material, with admissible fire resistance class according to the UNI 1350-1 standard [23]. From the experimental activity, in order to have the imbibition of used fibres, an amount of water of $30 \mathrm{~g}$ other than the starting quantity is needed. Additional specimens are manufactured with increased water amount aiming at evaluating their workability by shaking Table $\mathbf{5}$.

The previous table shows the values of the $(\mathrm{W} / \mathrm{L})_{\mathrm{tot}}$ ratio, which takes into account the total water in the mixture and is computed according to the following relationship:

$$
(W / L)_{\text {tot }}=\frac{W_{\text {grout }}+W_{\text {work }}}{P_{\text {grout }}}
$$

where $\mathrm{W}_{\text {grout }}$ is the water amount absorbed by the mixture, $\mathrm{W}_{\text {work }}$ is the water quantity needed for workability and $\mathrm{P}_{\text {grout }}$ is the mixture weight.

On the other hand, since the imbibition water is initially subtracted to the dough due to the hygroscopic nature of fibres, the $(\mathrm{W} / \mathrm{L})_{\text {eff }}$ parameter is introduced as follows:

$$
(W / L)_{\text {eff }}=\frac{W_{\text {grout }}+W_{\text {work }}-W_{f, \text { imb }}}{P_{\text {grout }}}
$$

where $\mathrm{W}_{\mathrm{f}, \mathrm{imb}}$ is the water amount absorbed by fibres.

\subsection{Optimal Percentage of Fibres}

The influence of fibres on the workability is evaluated by manufacturing samples with lime weight of $2000 \mathrm{~g}$, water weight of $400 \mathrm{~g}$, workability water $\left(\mathrm{W}_{\text {wor }}\right)$ of $30 \mathrm{~g}$ and imbibition water $\left(\mathrm{W}_{\mathrm{imb}}\right)$ as a variable parameter. In particular, $\mathrm{W}_{\mathrm{imb}}$ is dependent on the percentage of used fibres $\left(\%_{\mathrm{fib}}\right)$, assumed from $0,25 \%$ to $2,00 \%$ of the lime weight with a weight $\left(\mathrm{P}_{\text {fib }}\right)$ from $5 \mathrm{~g}$ to $30 \mathrm{~g}$, respectively. Therefore, the used $\mathrm{W} / \mathrm{L}$ ratio is a variable parameter depending on the total water weight $\left(\mathrm{W}_{\text {tot }}\right)$, which is sum of the initial water weight plus $\mathrm{W}_{\mathrm{imb}}$ plus $\mathrm{W}_{\text {work }}$. The different specimens prepared and the corresponding features are listed in Table 6, where the results of the workability tests are reported too. From the achieved results, it is noticed that the best percentage of fibres is $1 \%$, since a wet dough with proper workability features is found. Contrary, percentages higher than $1 \%$ do not allow to have the required dough consistency, as shown in Figs. (3 \& 4). 

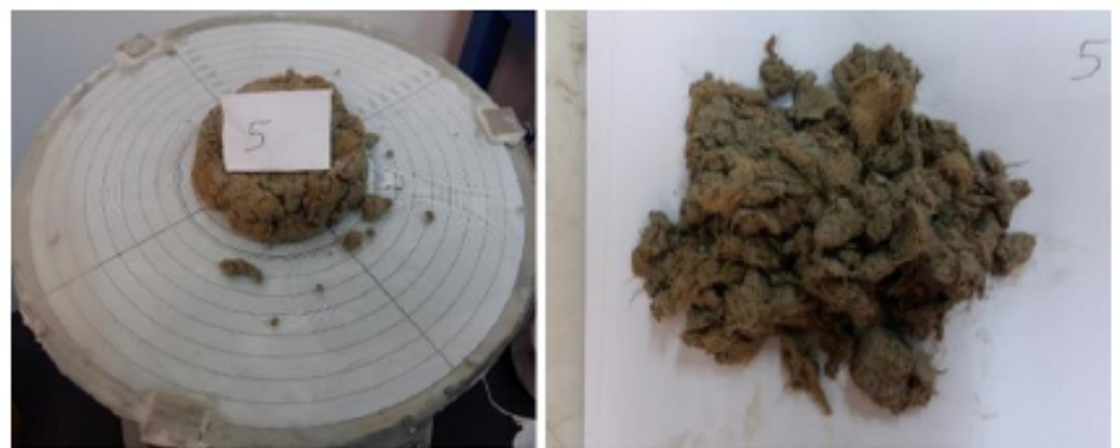

Fig. (3). Fibre-reinforced mortar sample with unsatisfactory consistency.

Table 6. Consistency tests on samples with different percentages of fibres.

\begin{tabular}{|c|c|c|c|c|c|c|c|}
\hline Sample & $\begin{array}{c}\mathbf{\%}_{\text {fib }} \\
(\mathbf{\%})\end{array}$ & $\begin{array}{c}\mathbf{P}_{\text {fib }} \\
\mathbf{( g )}\end{array}$ & $\begin{array}{c}\mathbf{W}_{\text {imb }} \\
\mathbf{( g )}\end{array}$ & $\begin{array}{c}\mathbf{W}_{\text {wor }} \\
\mathbf{( g )}\end{array}$ & $\begin{array}{c}\mathbf{W}_{\text {tot }} \\
(\mathbf{g})\end{array}$ & $\mathbf{W / L ~ r a t i o ~}$ & Spreading Value (mm) \\
\hline 1 & 0,0 & 0 & 0 & 30 & 430 & 0,215 & 190 \\
\hline 2 & 0,25 & 5 & 15 & 30 & 445 & 0,223 & 182 \\
\hline 3 & 0,50 & 10 & 30 & 30 & 460 & 0,230 & 180 \\
\hline 4 & 0,75 & 15 & 45 & 30 & 475 & 0,238 & 177 \\
\hline 5 & 1,00 & 20 & 60 & 30 & 490 & 0,245 & $(*)$ \\
\hline 6 & 1,50 & 25 & 75 & 30 & 505 & 0,253 & $(*)$ \\
\hline 7 & 2,00 & 30 & 90 & 30 & 520 & 0,260 & \\
\hline
\end{tabular}

(*) unsatisfactory consistency test

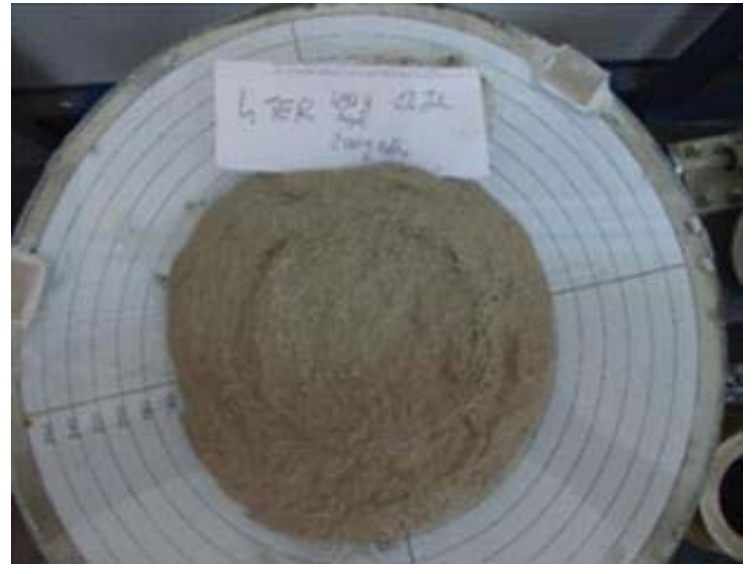

a)

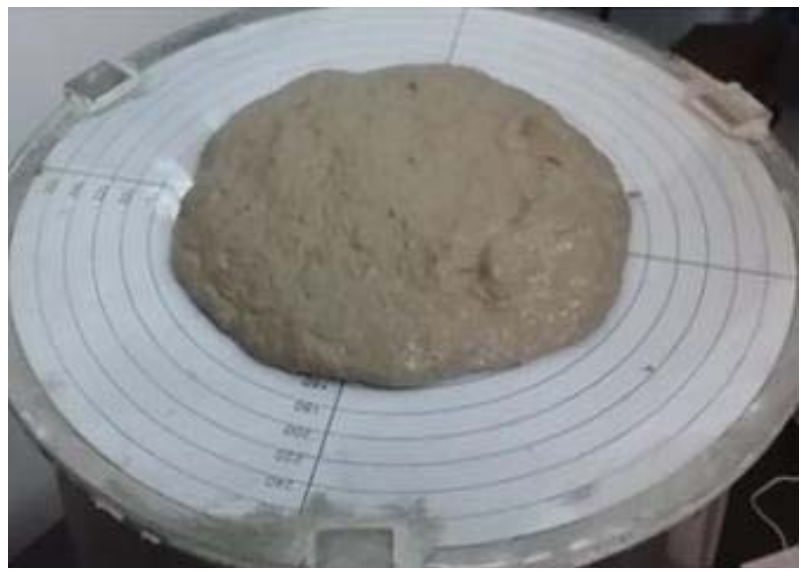

b)

Fig. (4). Fibre-reinforced mortar samples with semi-fluid (a) and super-fluid (b) consistency.

From the workability tests carried out, it is noticed that samples n. 6 and 7 have a very low consistency, so to make the mixtures unsuitable for constructions (Fig. 3). Ineffective mixtures for constructions are also those showing semi-fluid and super-fluid consistencies (Fig. 4b). Contrary, the dough with a fibre percentage of $1 \%$ shows the best consistency with a wet appearance (Fig. 5). 


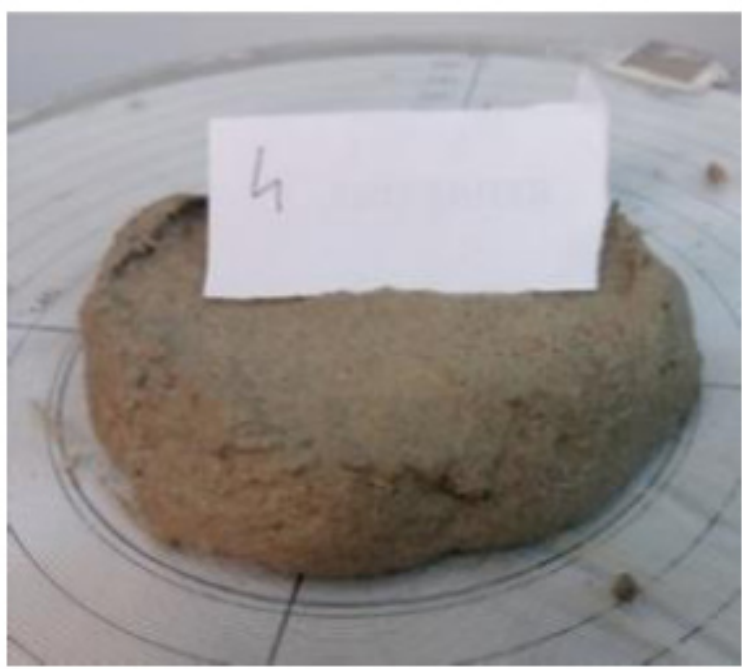

Fig. (5). Fibre-reinforced mortar sample with wet consistency.

\subsection{Workability and Consistency of the Mixture}

The spreading of the grout increases in a linear way as the $(\mathrm{W} / \mathrm{L})_{\text {tot }}$ ratio augments, attaining a maximum value of $21,5 \%$ (Fig. 6). For higher (W/L) tot values, spreading exceeds the limits indicated in the EN 998-1 standard [18]. The trend of spreading versus $(\mathrm{W} / \mathrm{L})_{\text {tot }}$ ratio is represented by a linear law, as shown in (Fig. 6) Comparing the linear behaviour with the envelope, an absolute error value $\mathrm{e}_{\max }=6.04 \%$ and and average error $\mathrm{e}_{\mathrm{med}}=4.98 \%$ are recorded. Analyzing the shaking table test data in terms of workability, when fibre percentage $(\% \mathrm{~F})$ of $1.0 \%$ is considered, it is observed that when the $(\mathrm{W} / \mathrm{L})_{\text {eff }}$ ratio increases, the spreading value growths as well with a linear law (Fig. 7). It is detected that the average error $\mathrm{e}_{\text {med }}$ is equal to $0.05 \%$, whereas the absolute value of the maximum error $\mathrm{e}_{\max }$ is equal to $1.79 \%$. Setting $(\mathrm{W} / \mathrm{L})_{\text {tot }}=21,5 \%$, a spreading $v s$. fibre percentage $(\% \mathrm{~F})$ linearly variable law, with an average error $\mathrm{e}_{\text {med }}=0.14 \%$ and a maximum error $\mathrm{e}_{\max }=5.74 \%$, is observed (Fig. 8).

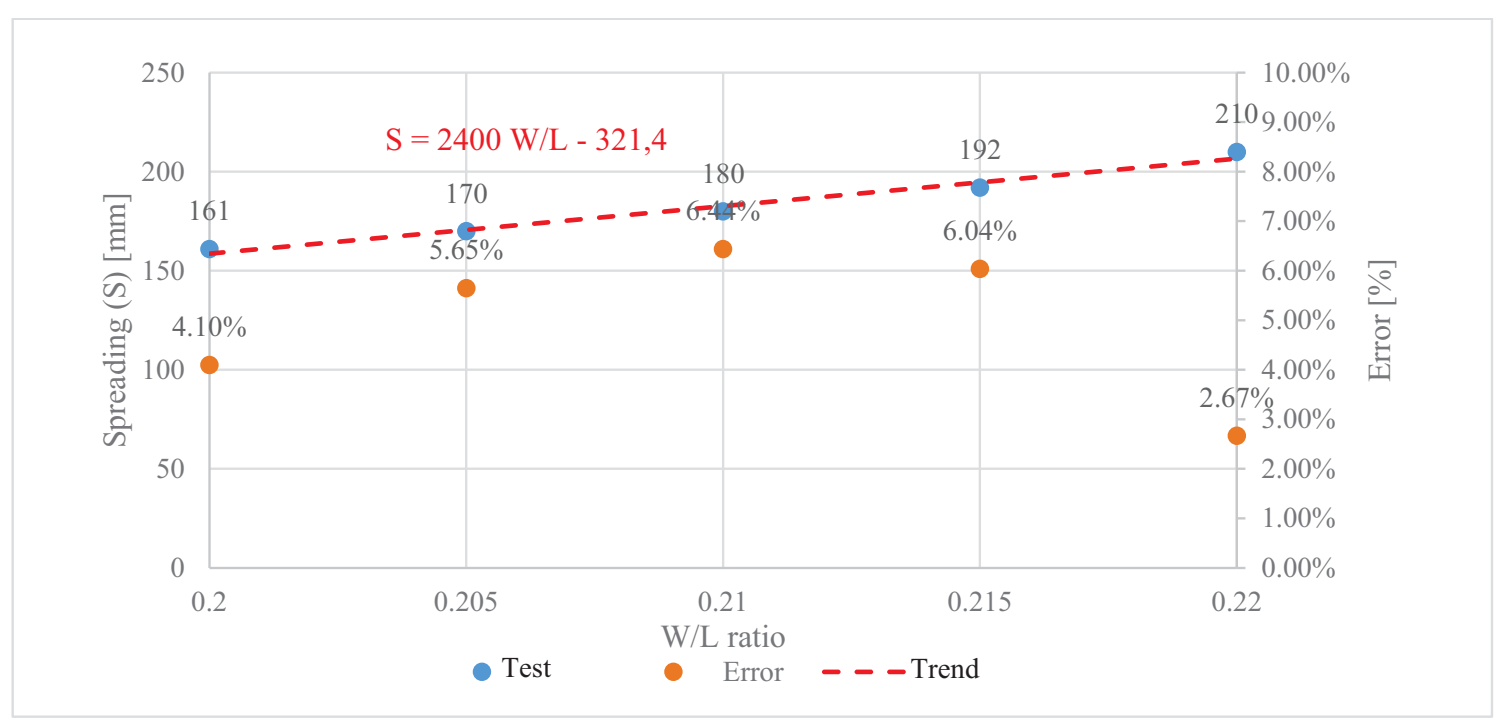

Fig. (6). Spreading $v s$. W/L ratio trend. 


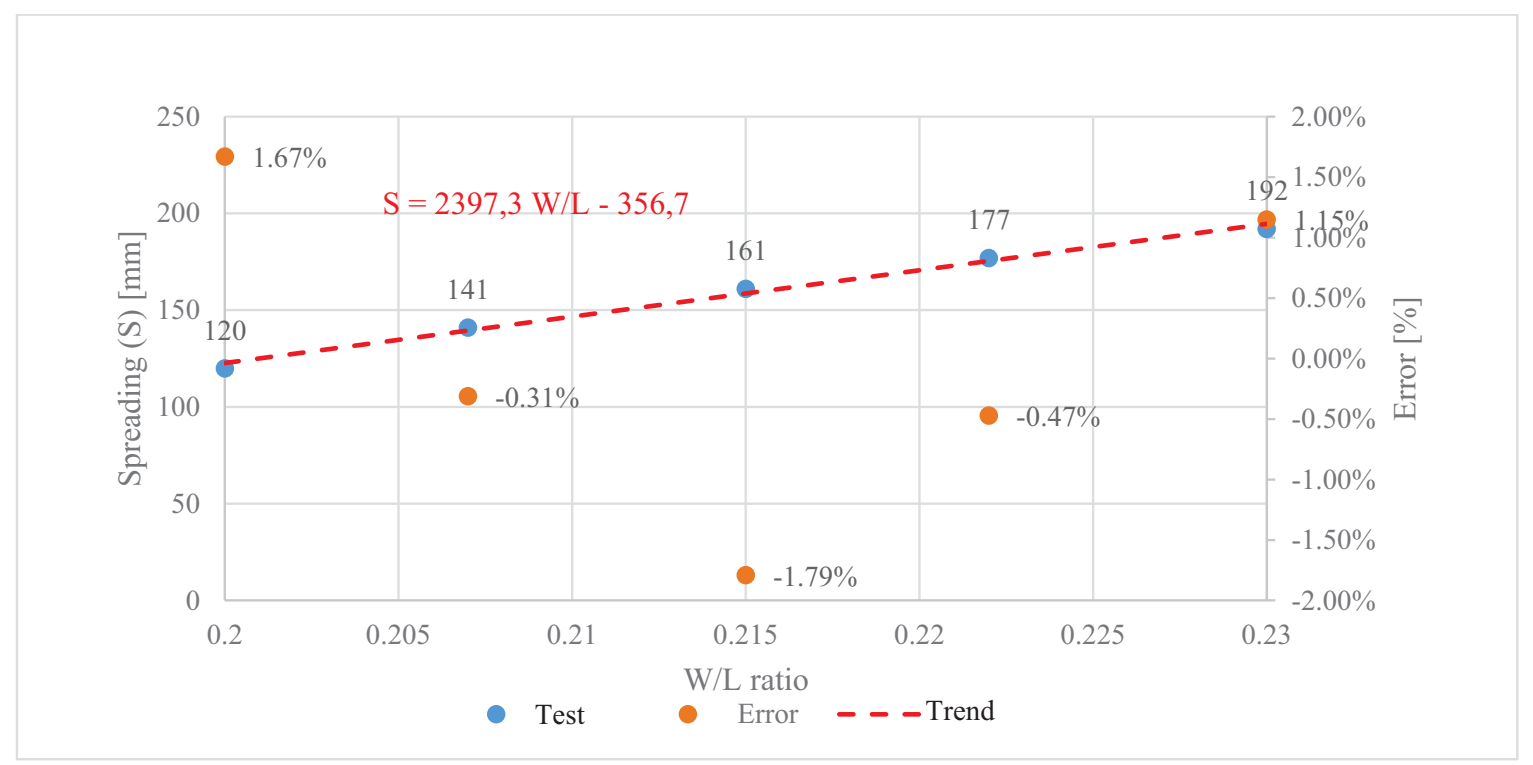

Fig. (7). Spreading $v s$. W/L ratio trend for samples with $\% \mathrm{~F}=1.0 \%$.

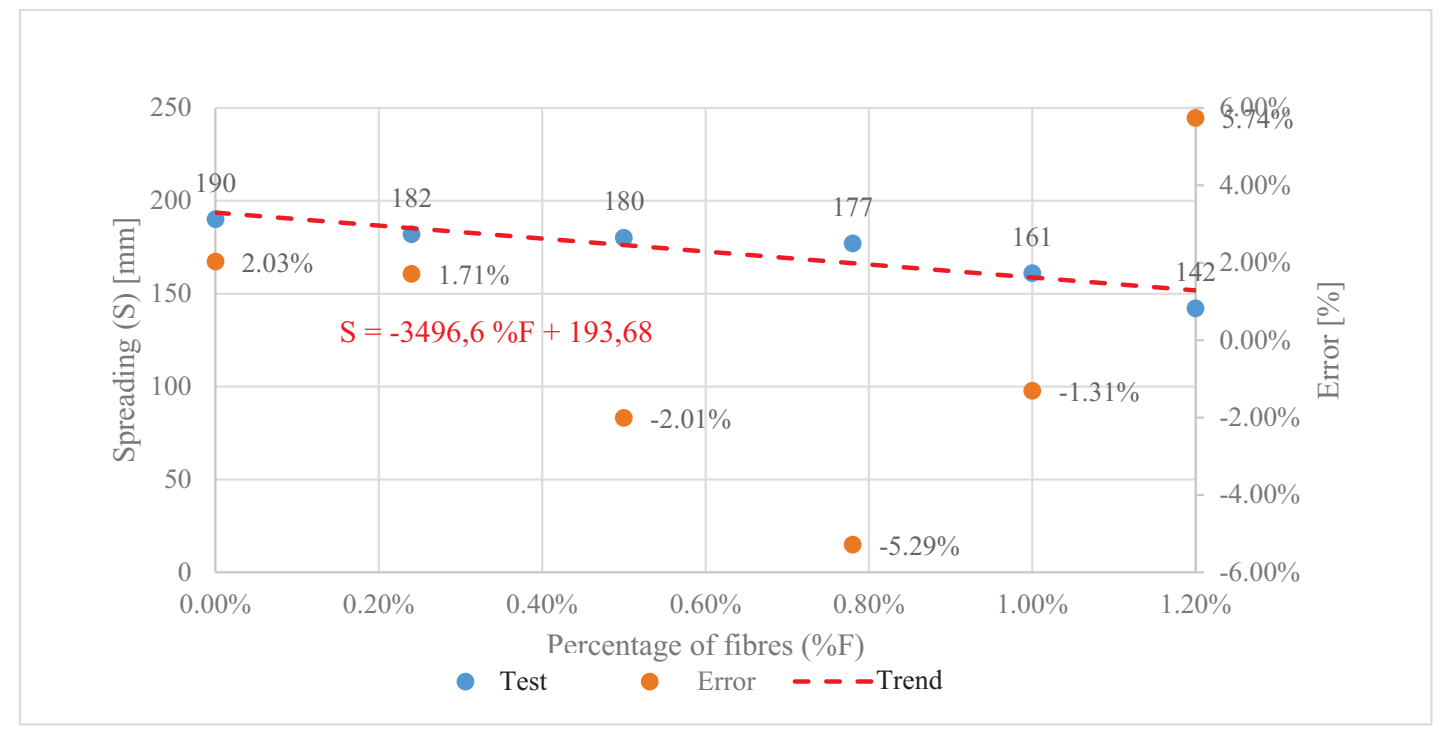

Fig. (8). Spreading $v s$. fibre percentage trend for samples with $(\mathrm{W} / \mathrm{L})_{\text {eff }}=21.5 \%$.

\subsection{Mechanical Tests}

Different specimens with dimensions of 40x40x160 mm are prepared for mechanical bending tests. They are characterised by a $\mathrm{W} / \mathrm{L}$ ratio of $21.5 \%$ and percentages of fibres of $0.25,0.50,0.75$ and $1.00 \%$. The performances of these samples are compared with those of unreinforced specimens. For each percentage of fibres, three specimens are manufactured (Fig. 9a). After 3 days, all of the specimens are removed from formworks and, later on, subjected to seasoning for 25 consecutive days under standard ambient conditions. At that time, the samples are weighted and measured to check the shrinkage effect, which is resulted negligible. After this phase, three-points bending tests are performed according to the UNI EN 1015-11 standard [24] (Fig. 9b). The achieved results in the force - displacement plane are depicted in (Fig. 10). The bending stress of specimens is calculated starting from the strength value $F_{\text {sd }}$ as follows:

$$
\sigma_{\text {bend }}=1.5 \frac{F_{s d} L_{0}}{b d^{2}}
$$

where the specimen width $\mathrm{b}$ and depth $\mathrm{d}$ are both $40 \mathrm{~mm}$ and $\mathrm{L}$ is the specimen length, equal to $110 \mathrm{~mm}$. 
From the tests, it is noticed that unreinforced samples have a brittle type failure, with the collapse attained when the first crack appears. On the other hand, when fibres are added to the mixtures, the behaviour is changed from brittle type to pseudoductile one. From the experimental point of view, the first crack in the lime mortar matrix gives rise to a gradual strength reduction with a pseudo-ductile softening branch. This is due to the stitching effect provided by jute fibres, which contribute to increase the specimen ultimate displacement after the maximum strength is attained. In particular, the fibrereinforced samples show an average decrease of the unreinforced samples failure strength of about $10 \%$. Contrary, the presence of fibres allows to increase the mean ultimate displacement of unreinforced samples of about $15 \%$. The ductile behaviour of fibre-reinforced mortars is much more visible as the percentage of fibres increases. Particularly, the best behaviour is attained when $1 \%$ of jute fibres is considered. In this case, the maximum failure displacement is resulted to be $66,9 \%$ greater than that of the unreinforced specimen. A clear picture of the benefit deriving from the presence of fibres in the

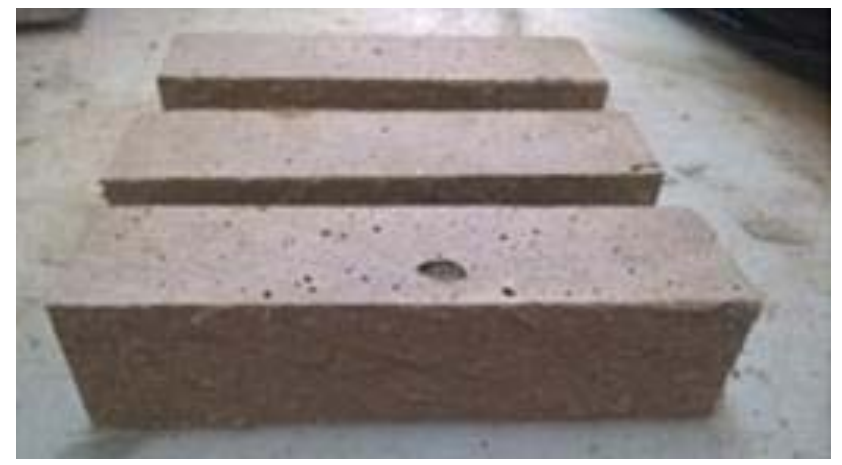

a)

Fig. (9). A set of prepared samples (a) and the three-points bending test (b).

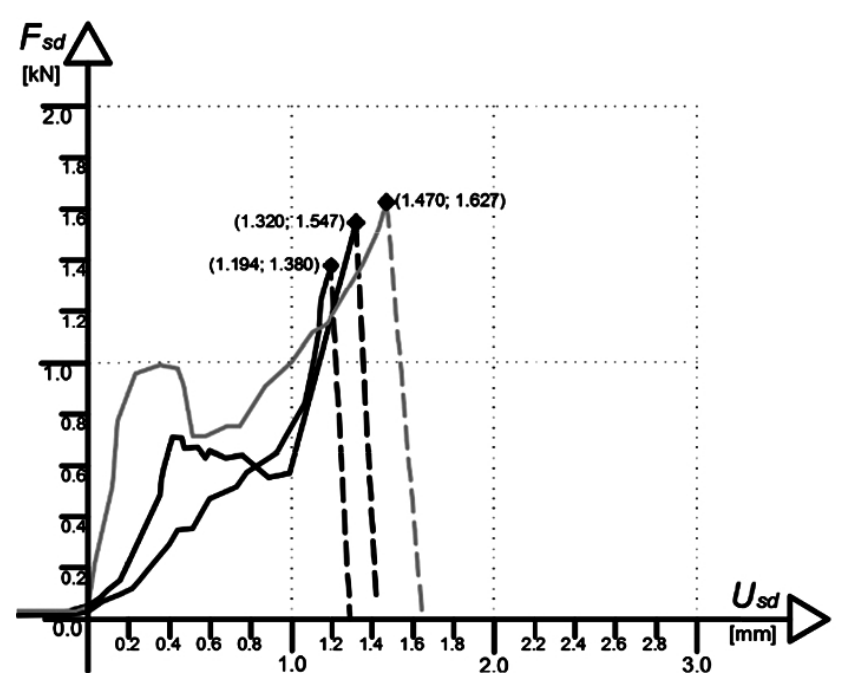

a) lime mortar sample is depicted in Fig. (11).

Subsequently, the half samples deriving from bending tests are joined together with high-strength cement mortar in order to make cubic specimens to be subjected to compression tests [25].

The test results in terms of average failure compression stress are shown in Fig. (12). In this figure, it is noticed that all investigated fibre-reinforced mortars with percentage of fibres less than $1 \%$ have average compression stress greater than 10 MPa [26].

On the other hand, when $1 \%$ of fibres are used, a stress reduction of about $25 \%$ with respect to the unreinforced specimen one occurs. This is due to the insertion in the dough of fibres having density lesser than that of the lime mortar. Nevertheless, in this case, the attained average failure stress is almost equal to the M10 mortar one. This means that all the examined fibre-reinforced mortars can be used as building products in the seismic zone according to the actual Italian technical code NTC 2018 [27].

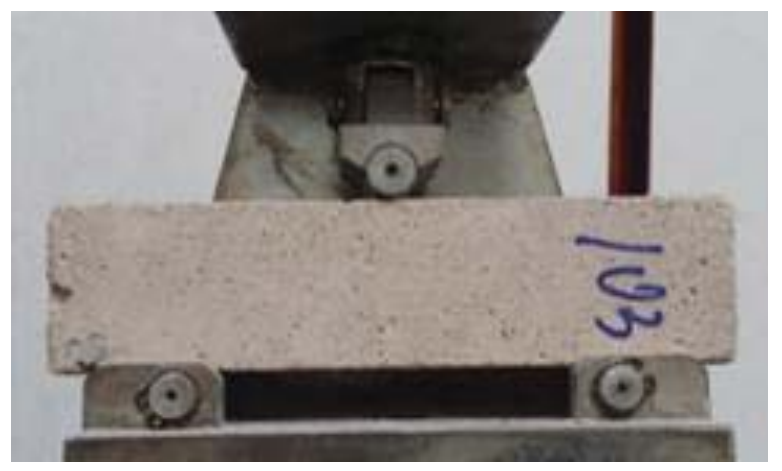

b)

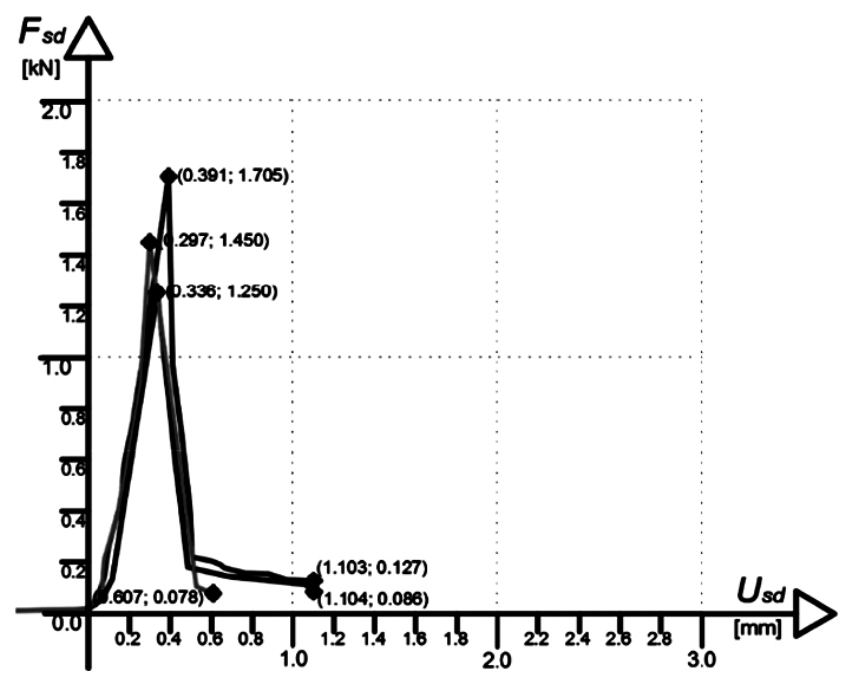

b)

Fig. $1 \square$ cont..... 


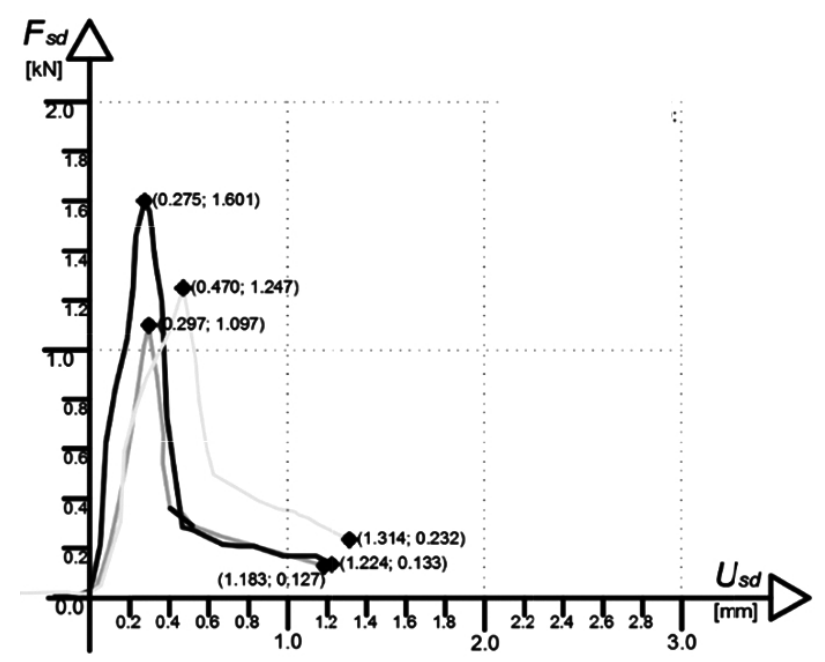

c)

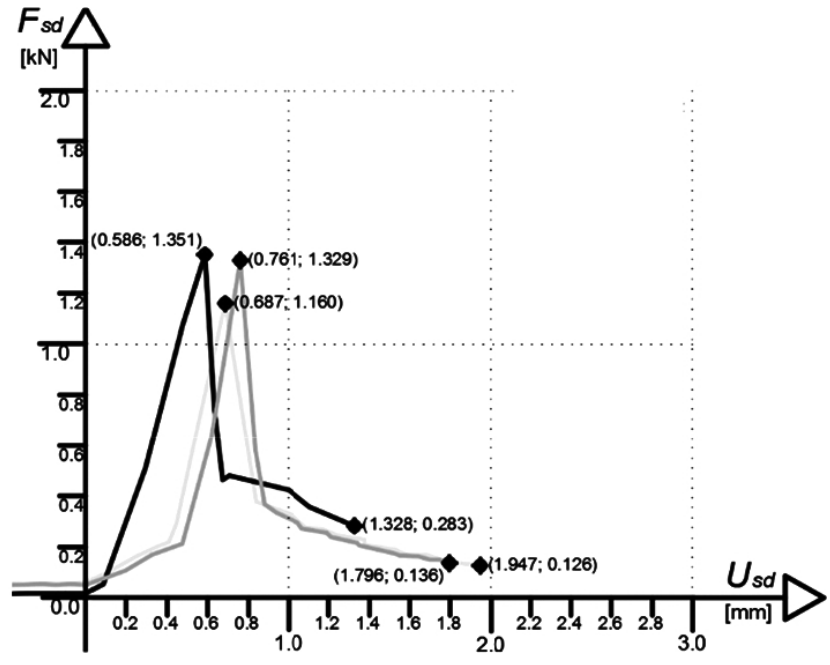

d)

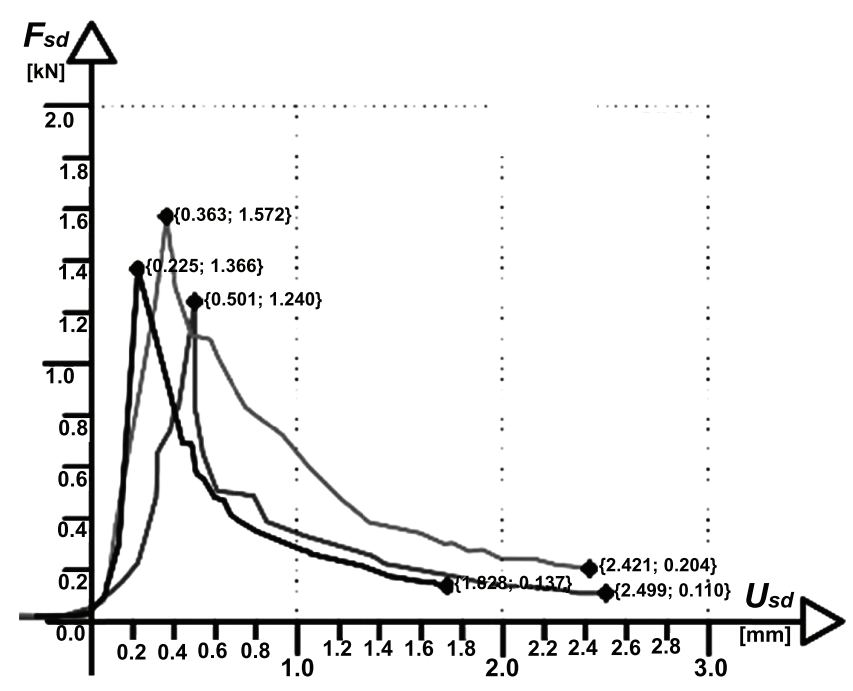

e)

Fig. (10). Force-displacement bending curves of samples without fibres (a) and with percentage of fibres equal to $0,25 \%$ (b), $0,50 \%$ (c), $0,75 \%$ (d) and $1,00 \%$ (e).
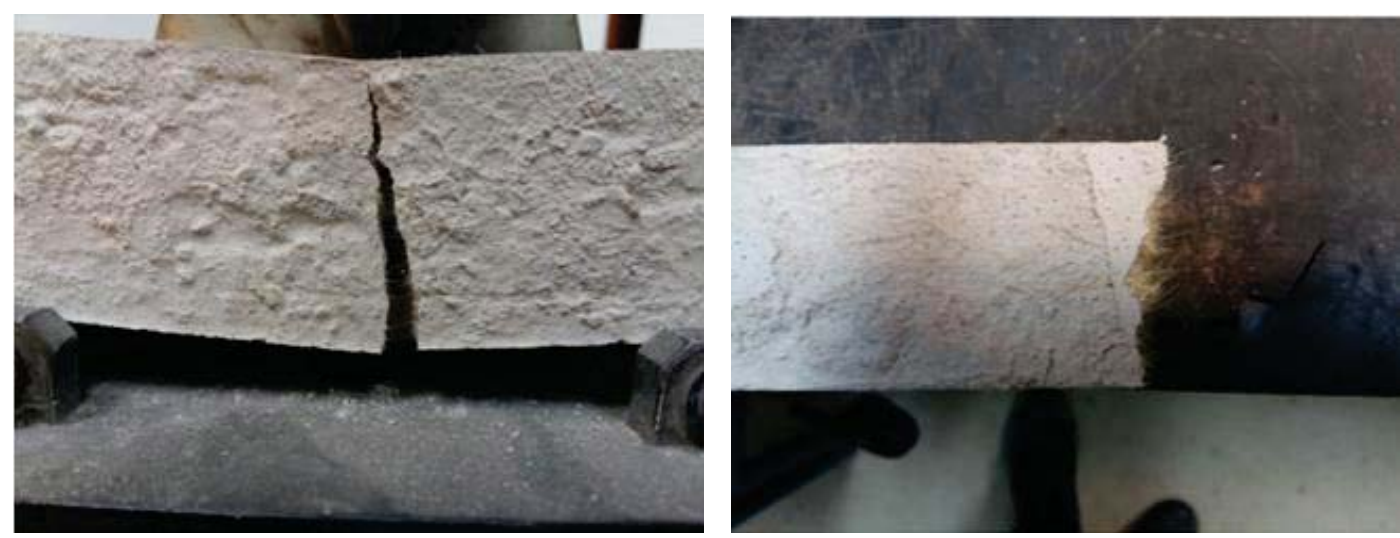

Fig. (11). Stitching effect provided by jute fibres in the bending test. 


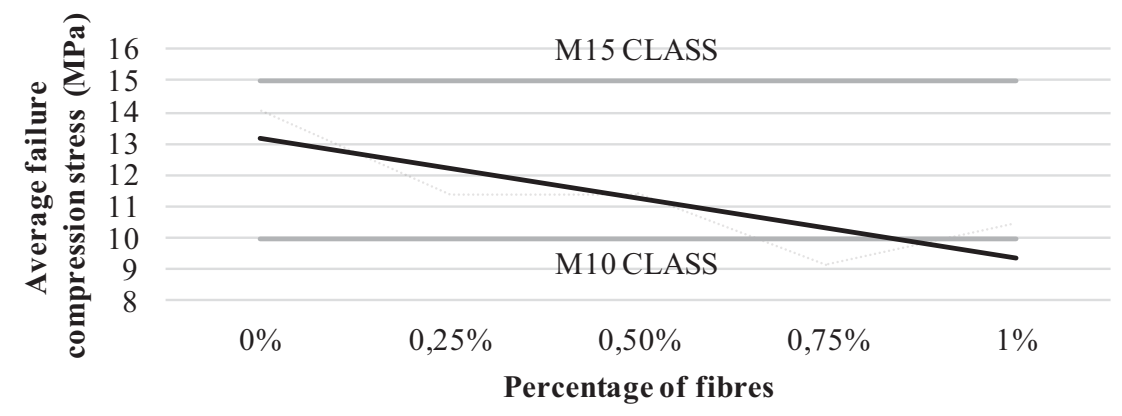

Fig. (12). Results of compression tests: variation of average failure compression stress with the percentage of fibres.

\section{CONCLUSION}

In the current paper experimental tests on lime mortars strengthened with raw jute fibres have been presented and discussed.

Physical and mechanical tests have been carried out on samples reinforced with different percentages of jute fibres and the analysis results have been compared to those related to unreinforced specimens. From one side, the workability physical test of the fibre-reinforced mixtures by shaking table has been evaluated. On the other side, three-points bending and compression tests have been performed as laboratory mechanical experiments.

The physical tests have evidenced the high hygroscopic capacity of jute fibres, having length between 5 and $15 \mathrm{~mm}$, which are able to absorb water up to three times their weight. Moreover, it has been observed that the optimal water/lime ratio of fibre-reinforced mortars is equal to $21,5 \%$. In this case, with a weight percentage of jute fibres equal to $1 \%$, the dough workability limit for structural use is reached. Contrary, for percentages of fibres less than $1 \%$, the dough workability is progressively reduced, so to have products without the required consistency.

The bending tests have shown the benefit deriving from the presence of jute fibres, which provide a stitching effect of cracks. This makes as pseudo-ductile the behaviour of investigated fibre-reinforced lime mortars, which have shown an average ultimate displacement about $15 \%$ greater than that of the unreinforced samples. Such a beneficial behaviour has been much more noticeable when $1 \%$ of fibres have been employed. In this case, a maximum failure displacement about $67 \%$ greater than the unreinforced mortar specimen one has been detected.

Finally, compression tests have proved that all of the inspected reinforced samples can be classified as a M10 lime mortar. This has been also occurred with the sample manufactured with $1 \%$ of jute fibres, which has exhibited a stress about $25 \%$ lesser than the unreinforced specimen one. In conclusion, the examined fibre-reinforced mortars can be used as building products in seismic zone according to the actual Italian technical code NTC 2018. To this purpose, additional experimental tests will be performed as future research development in order to validate the obtained results.

\section{CONSENT FOR PUBLICATION}

Not applicable.

\section{AVAILABILITY OF DATA AND MATERIALS}

The authors confirm that the data supporting the findings of this study are available within the article.

\section{FUNDING}

None.

\section{CONFLICT OF INTEREST}

The authors declare no conflict of interest, financial or otherwise.

\section{ACKNOWLEDGEMENTS}

The authors would like to acknowledge the Tecnolab s.r.l. laboratory of Naples and its Technical Director Eng. Andrea Basile for providing the equipments used for experimental activities.

\section{REFERENCES}

[1] Italian National Institute of Statistics (ISTAT), $15^{\text {th }}$ General Census of Population and Housing (in Italian), 2011.

[2] S. Noor-E-Khuda, M. Dhanasekar, and D.P. Thambiratnam, "Out-ofplane deformation and failure of masonry walls with various forms of reinforcement", Compos. Struct., vol. 140, pp. 262-277, 2016. [http://dx.doi.org/10.1016/j.compstruct.2015.12.028]

[3] S. Noor-E-Khuda, and M. Dhanasekar, "Three sides supported unreinforced masonry walls under multidirectional loading", Constr. Build. Mater., vol. 188, pp. 1207-1220, 2018. [http://dx.doi.org/10.1016/j.conbuildmat.2018.08.144]

[4] E. Grande, G. Milani, and E. Sacco, "Modelling and analysis of FRPstrengthened masonry panels", Eng. Struct., vol. 30, no. 7, pp. 1842-1860, 2008.

[http://dx.doi.org/10.1016/j.engstruct.2007.12.007]

[5] A.K. Bledzki, S. Reihmane, and J. Gassan, "Properties and modification methods for vegetable fibers for natural fiber composites", J. Appl. Polym. Sci., vol. 59, no. 8, pp. 1329-1336, 1996. [http://dx.doi.org/10.1002/(SICI)1097-4628(19960222)59:8<1329::AI D-APP17>3.0.CO;2-0]

[6] M.P.M. Dicker, P.F. Duckworth, A.B. Baker, G. Francois, M.K. Hazzard, and P.M. Weaver, "Green composites: A review of material attributes and complementary applications", Compos., Part A Appl. Sci. Manuf., vol. 56, pp. 280-289, 2014.

[http://dx.doi.org/10.1016/j.compositesa.2013.10.014]

[7] M. Ali, "Natural fibres as construction materials", J. Civil. Engin. Construct. Technol., vol. 3, no. 3, pp. 80-89, 2012.

[8] S. Shahinur, M. Hasan, Q. Ahsan, D.K. Saha, and M.S. Islam, "Characterization on the properties of jute fiber at different portions", 
Int. J. Polym. Sci. Article ID, vol. 262348, pp. 1-6, 2015 [http://dx.doi.org/10.1155/2015/262348]

[9] M.K. Sridhar, G. Basavarajappa, S.G. Kasturi, and N. Balasubramanian, "Evaluation of jute as a reinforcement in composites", Ind. J. Text. Res., vol. 7, pp. 87-92, 1982.

[10] H.S. Ramaswamy, B.M. Ahuja, and S. Krishnamoorthy, "Behaviour of concrete reinforced with jute, coir and bamboo fibres", Int. J. Cement Compos. Lightweight Concrete., vol. 5, no. 1, pp. 3-13, 1983. [http://dx.doi.org/10.1016/0262-5075(83)90044-1]

[11] H.E. Gram, Durability of natural fibres in concrete., Research Institute, 1983, p. 225.

[12] A. Formisano, E.J. Dessì, and R. Landolfo, "Mechanical-physical experimental tests on lime mortars and bricks reinforced with hemp", AIP Conf. Proc., vol. 1906, 2017.090006 [http://dx.doi.org/10.1063/1.5012363]

[13] A. Formisano, F. Fabbrocino, E.J. Dessì, and G. Chiumiento, "Experimental shear tests on tuff blocks triplets with hemp fibres reinforced lime mortar", Proc of the $23^{\text {rd }}$ Conference of the Italian Association of Theoretical and Applied Mechanics (AIMETA 2017), vol. Vol. 2, pp. 2022-2028 Salerno, Italy

[14] S. Noor-E-Khuda, and F. Albermani, "Mechanical properties of clay masonry units: Destructive and ultrasonic testing", Constr. Build. Mater., vol. 219, pp. 111-120, 2019.

[http://dx.doi.org/10.1016/j.conbuildmat.2019.05.166]

[15] S. Noor-E-Khuda, F. Albermani, and M. Veidt, "Flexural strength of weathered granites: Influence of freeze and thaw cycles", Constr. Build. Mater., vol. 156, pp. 891-901, 2017.

[http://dx.doi.org/10.1016/j.conbuildmat.2017.09.049]

[16] F. Kesikidou, and M. Stefanidou, "Natural fiber-reinforced mortars", $J$. Build. Eng., vol. 25, 2019.

[http://dx.doi.org/10.1016/j.jobe.2019.100786]

[17] A. Miano, F. Jalayer, and A. Prota, "Considering structural modeling uncertainties using bayesian cloud analysis", Proc. of the $6^{\text {th }}$ ECCOMAS Thematic Conference on Computational Methods in Structural Dynamics and Earthquake Engineering (COMPDYN 2017),
2017 Rhodes, Greece

18] UNI EN 998-1, Specifications for mortars into masonry artifacts Part 1: Mortars for internal and external plasters., Italian standardization body: Rome, Italy, 2019

19] UNI EN 998-2, Specifications for mortars into masonry artefacts Part 2: Mortars for masonry., Italian standardization body: Rome, Italy, 2016.

[20] UNI EN 196-1, Testing methods on cements - Part 1: Determination of the mechanical strengths., Italian standardization body: Rome, Italy, 2005.

[21] UNI EN 1015-3, Testing methods for mortars into masonry artefacts Part 3: Determination of the consistency of fresh mortar (by shaking table)., Italian standardization body: Rome, Italy, 2007.

22] S. Noor-E-Khuda, and F. Albermani, "Flexural strength of weathered granites under wetting - drying cycles: Implications to steel structures", Adv. Steel Constr., vol. 15, no. 3, pp. 225-231, 2019.

[23] UNI EN 1350-1-1, Fire classification of products and building elements - Part 1: Classification based on fire reaction test results., Italian standardization body: Rome, Italy, 2009.

[24] F. Kesikidou, and M. Stefanidou, "Natural fiber-reinforced mortars", $J$. Build. Eng., vol. 25, 2019. [http://dx.doi.org/10.1016/j.jobe.2019.100786]

[25] P. Zak, T. Ashour, A. Korjenic, S. Korjenic, and W. Wu, "The influence of natural reinforcement fiWu, gypsum and cement on compressive strength of earth bricks materials", Constr. Build. Mater., pp. 179-188, 2016.

[http://dx.doi.org/10.1016/j.conbuildmat.2015.12.031]

[26] G. Chiumiento, A. Formisano, and F. Fabbrocino, "Experimentation on lime mortars reinforced with jute fibres: mixture workability and bending resistance", Lecture Notes in Mechanical Engineering, pp. 1869-1880, 2020 .

[http://dx.doi.org/10.1007/978-3-030-41057-5 150]

[27] Ministry of Infrastructures and Transports, "Ministerial Decree 17 January 2018, Updating of Technical Codes for Constructions (in Italian)", Official Gazette n. 42 of 20/02/18, Ordinary Supplement n. 8, Rome, Italy, 2018., 2018.

\section{(C) 2020 Formisano et al.}

This is an open access article distributed under the terms of the Creative Commons Attribution 4.0 International Public License (CC-BY 4.0), a copy of which is available at: (https://creativecommons.org/licenses/by/4.0/legalcode). This license permits unrestricted use, distribution, and reproduction in any medium, provided the original author and source are credited. 